\title{
Regions Lobbying the European Union: Organizational Forms, Policy Portfolios and Venue Selection
}

\author{
Dr Bert Fraussen (Australian National University and University of Antwerp) \\ Dr Tom Donas (University of Antwerp)
}

\section{Introduction}

During the past decades, significant changes have taken place in the European political order, as nation states were challenged by three fundamental developments. Since the 1960s, almost all Western European states have decentralized some policymaking competences to meso-level authorities, that is, political entities situated between the national and the local level of governance (Hooghe et al. 2010). As a result, these subnational authorities (SNAs) nowadays play a much more important role in policymaking processes and the provision of public goods to citizens. Almost simultaneously, a second development took place, as the European Union (EU) engendered a transfer of power and a pooling of sovereignty from the nation states to supranational institutions. Furthermore, national governments also increasingly started delegating critical tasks to other public and private agents, resulting in a closer involvement of other organizations in policymaking and a blurring of the boundaries between public and private spheres. Hence, a trend towards decentralization was accompanied by an upward competence pull resulting from deepening European integration, as well as a broadening of networks of governance.

As many public policies are increasingly initiated and shaped at the European level, this has become an increasingly relevant political venue for political elites, including those at the subnational level. Policy domains in which substantial quantities of EU law have to be implemented frequently are often the competences assigned to subnational entities, for example, education, health and environmental affairs. Furthermore, a considerable number of EU policies have a direct or indirect effect on sub-state interests. These policies include redistributive matters (such as the Cohesion and Structural Funds, as well as the Common Agricultural Policy), yet also regulatory initiatives and policy programs (for instance in the area of transport and infrastructure) that affect the economic competitiveness of regional entities. Moreover, since the dynamics of the single market considerably affect the economic room for manoeuvre of regional political elites, the European integrated economy, rather than the national economy, has become a crucial point of reference for them. 
Notwithstanding this increased level of interdependence, key European institutions, such as the Council of Ministers and the European Parliament, formally still primarily rely on member-states positions, or the voice of directly elected representatives. As a result, the representation of regional and sub-state interests in the European political order remains rather informal and indirect. Nevertheless, a haphazard or arbitrary representation of sub-state interests could contribute to a problem of input-legitimacy (Scharpf 1999). That is, in many member states, political consensus building and processes of accountability take place at the regional level, while it is the central government that represents these member states in the EU. Without any sub-state representation, the EU could give rise to a sort of representational gap for such countries. A shortage of regional input in policymaking processes might furthermore also affect output-legitimacy, or the quality of EU policies. Regional policymakers have often acquired considerable expertise and experience concerning particular EU policies, as they are quite regularly involved in the implementation and execution of EU distributive and regulatory policies. This knowhow could be highly relevant to EU-level policymakers when new political initiatives are being developed, or at times when existing legislation is being evaluated or revised.

In this chapter, we zoom in on the organizational forms, policy portfolios and venue selection of regions at the EU level. We first provide a literature review and address how multilevel governance shapes the relations between subnational authorities and the central government. Next, we discuss the scope and diversity of EUlevel territorial mobilization, and clarify why some sub-state jurisdictions are more likely to be active at the supranational level. Subsequently, we analyse the activities of these regional representations in Brussels by taking a closer look at the amount and the nature of the policy issues that these regions focus on, as well as the particular institutional venues that they prioritize in their lobbying activities.

\section{Regional authorities, the nation state and multilevel governance}

The extent to which the European political system can be characterized as a governmental arena, in which the member-states still play a predominant and central role, represents a fundamental question in political science (Marks et al. 1996; Moravcsik 1998). The study of regional authorities and their involvement in EU-affairs is considered quintessential in this debate, as it provides a key case to observe the possible 
implications of the up- and downward transfer of policy competences (Hooghe 1995, 1996; Hooghe and Marks 1996).

Regarding the development of research on the interplay between subnational authorities, national governments and the EU institutions, Marks and Hooghe's early work on regional and structural policymaking, in which they developed the concept of multilevel governance, has had a great impact (Marks 1992, 1993; Hooghe and Marks 2001). One of their core expectations was that the potential redistributive impact of EU regional policymaking would energize and stimulate regional interest representation. When establishing regional policies (such as Cohesion and Structural funding), EU policymakers and in particular the European Commission may prefer to directly interact with regional interests. This enables them, at times, to bypass central state executives, or to diminish the influence of central state executives in some EU matters. This pattern became particularly manifest with the establishment of the cohesion policy in the mid1980s. In addition, the EU facilitated the construction of a dynamic meso-level, for instance by establishing the NUTS-nomenclature ${ }^{1}$, making structural funds conditional on specific administrative and institutional conditions and involving regional authorities in the execution of these programs, as well as by encouraging trans-regional collaboration (for instance via its INTERREG-program).

Another point of view, however, is that central government executives still have considerable capabilities to constrain or weaken the autonomy and discretion of substate entities. Scholars have for instance argued that precisely these various acts of downward and upward - delegation enable European nation states to maintain their central role, albeit in a different form (Bache and Jones 2000; Beyers and Bursens 2013). State-centered scholars frequently highlight the enduring gate-keeping capacities of central state executives within the European political order (Moravcsik 1998). In contrast to the initial expectations concerning multilevel governance, recent research in this area has showed that the combination of European integration and processes of devolution and regionalization has not led to a hollowing out of central government agencies and ministries, nor undermined the importance of the member-states. Rather than bypassing the central state, work in this field has increasingly demonstrated that sub-state authorities actually collaborate intensively with central state agencies in many

\footnotetext{
${ }^{1}$ For an explanation of NUTS see http://epp.eurostat.ec.europa.eu/portal/page/portal/nuts nomenclature/introduction (accessed December 2014)
} 
countries, and do not tend to bypass central state agencies (Tatham 2008, 2010, 2012; Moore 2008).

\section{Mobilization of regional authorities in Brussels}

Subnational authorities (SNAs), such as regions, provinces and cities, are increasingly mobilized at the European level. Much research has been conducted on the liaison offices, the individual presences of subnational executives in Brussels. Over time, the number of these offices has increased tremendously, from about 54 in 1993 (see Marks et al. 1996) to more than 200 today, a development that closely follows the process of EU enlargement. One of the most well-known examples probably involves the regional representation of Bavaria, which is located in the historic building of the former Institut Pasteur, only a few meters away from the European Parliament. In a previous project, that aimed to describe and clarify the representation of SNAs in Brussels, it was demonstrated that SNAs often rely on multiple organizational forms (Donas and Beyers 2013). This project only included SNAs that are located at the first level below the central government and that have an average population of more than 150,000 people; while it also excluded deconcentrated administrative units $(n=297)$. Applying this definition, it became clear that many SNAs have established a Brussel's or liaison office $(n=175)$. The resources that these offices have at their disposal vary greatly. While there are a few offices that have a staff of more than twenty employees, such as the representations of some German regions or Länder, most of them employ a rather limited amount of people (median $=4$ ). Yet the scope and diversity of territorial representation in Brussels is much broader than these individual representations. In some cases, SNAs from a similar country join forces to create a national association, enabling them to share the costs of establishing a presence in Brussels. In this regard, we can distinguish between complete national associations, including all SNAs of one member-state (for instance, the Irish Regions Office or the Danish Regions Office), and partial national associations, which gather only some SNAs of the same country, (such as the joint office of Hamburg and Schleswig-Holstein, or the North-Sweden European Office which combines the representation of Norrbotten County and Västerbotten County).

As well as these national associations, regions also frequently engage in another form of collective action, namely trans-regional associations, which group multiple 
regions from different countries. About 95 percent of the identified SNAs were member of one of the 68 trans-regional associations at the time of writing. While some of these trans-regional associations have a rather generalist orientation, such as the AER, the Assembly of European Regions, others are narrower in scope and focus on a particular policy field or topic. Examples of his last category include trans-regional associations such as the Airport Regions Conference (ARC) or the European Textile Collectivities Association (ACTE). Trans-regional associations generally group regions that have a common interest in a certain policy field, or similar policy preferences on certain topics. Through these associations, regions can exchange information and coordinate their strategies in a more structured way. Especially in the EU's highly crowded policy environment, these collective forms of representation, as noted elsewhere in this collection, can be quite valuable, as they facilitate information flows. Likewise, policymakers are often more sensitive to the demands of associations, compared to requests from individual offices, demonstrating the value of collective action in the EU policy process.

[table 1 here]

This broader perspective leads to the conclusion that the scope and diversity of EU-level territorial mobilization is much more extensive than generally considered. Yet, an important question involves whether there is a bias in the representation of regional interests, for instance if it is skewed towards resourceful and politically powerful regions. The fact that a large variety of regions are, in one form or another, represented in Brussels, indicates that sub-state representation at the EU level has become quite common. Yet, there are substantial differences regarding the (degree of) representation of different types of regions. While one conclusion could be that peripheral regions might benefit from the opportunity to directly mobilize in Brussels, especially resourcefull SNAs, SNAs benefiting from a high level of self-rule, and SNAs harboring regionalist political parties, are relatively more active in Brussels (Donas and Beyers 2013). These regions more frequently establish a liaison office, and also are more likely to occupy a prominent position in various trans-regional associations. The combination of organizational forms allows these SNAs to mobilize a large variety of 'policy goods' and to considerably improve their chances of gaining attention from EU policymakers. In the 
remainder of this chapter, we will take a closer look at the role of liaison offices, and address their activities in Brussels in more detail.

\section{Policy portfolios}

Brussels liaison offices can be considered as communication channels or intermediaries between regions and EU institutions. As they seek to represent territorial interests of both a public and private nature, their policy interests can be rather broad and diverse. Given that their resources are generally quite limited, however, they will not be able to take action on all policy issues that are potentially of interest to them but rather prioritise in terms of which policy areas it is possible to most effectively engage in, in order to gain maximum advantage for their particular region. Therefore, it is interesting to explore how these offices translate their rather general mission into specific political activities, which offer more insight into the type of interests that these regional lobbyists represent. In the next paragraphs, we will briefly discuss the policy portfolio of these organizations, the set of domains and policy issues in which they invest resources.

An analysis of the policy portfolio of 127 regional representations demonstrated that they mostly have a quite generalist orientation (Donas et al. 2014). On average, these actors indicated to monitor developments in about 11 policy domains, which implies that their policy interests in Brussels are usually quite broad and encompassing. However, their lobbying activities in the past six months proved to be much more restricted, and generally remain limited to two or three legislative issues. Hence, while these regional representations might monitor several policy fields, they only prioritize a fairly limited number of legislative issues in their lobbying behavior. If these issues are considered in more detail, and linked to the Directorate-Generals of the European Commission (DGs) it is DG REGIO that attracts most lobbying activity. The great majority (84 percent) of regional offices that monitor policy issues related to this DG also engaged in actual lobbying activities on these matters. For the other DGs, in contrast, the activities of the regional representations mostly remain limited to monitoring policy developments.

Another way to assess the policy portfolios of these regional representations is to consider the type of issues which they prioritize. If we distinguish between regulatory and redistributive issues, it seems that three types of regional representations can be 
identified. First, there is a group of offices that primarily focuses on monitoring, and thus rarely engages in lobbying on specific policy issues. Next, there is a large set of representations that do frequently engage in lobbying. Yet, their actions are mostly restricted to redistributive issues, for instance the reform of the Common Agricultural Policy, for instance, or Cohesion Policy. Finally, a small minority of regional representations not only lobbies on redistributive issues, but also demonstrates activity on issues of regulatory nature, like the Air Quality Directive or the Financial Transaction Tax. These are mostly regions that enjoy much autonomy and also have established ties with subnational private actors. For instance, regions that also focused on regulatory matters frequently reported relations with regional private interests, such as employer associations and companies within specific sectors. Often, these private actors were involved in the organization's governance, for instance through staff seconded from private sector specialists, or representation of these actors in advisory groups or the board of the organization. Regions who mostly lobbied on redistributive issues did not share these organizational features, but rather had important connections to transregional associations. As a result, it appears that the size and the nature of a policy portfolio is not primarily affected by the capacity of an office in terms of staff, but also results from its connections to other public and private interests. This suggests that the interests that regional offices represent are considerably affected by the input they receive from other societal actors.

\section{Venue selection}

Policymaking in the EU has often been depicted as a multilevel, multi-institutional process, offering organized interest multiple avenues to consider for exercising policy influence (Greenwood 2003; Coen and Richardson 2009). However, while regional representatives can interact with a mix of national (such as the Permanent Representation) and supranational institutions (like the European Parliament and the European Commission), due to constraints in time and resources they cannot engage with all possible venues and actors. This third part of the chapter will focus on the extent to which regional representations focus on multiple venues, or rather prioritize interaction with certain institutions in their lobbying activities.

Broadly speaking, a regional representation can be expected to focus on four key institutions in Brussels when seeking to influence a specific policy proposal, namely the 
EU Commission, the EU Parliament, the Committee of the Regions and the Permanent Representation (PR) of its home country (whose officials are involved in Council working groups and meetings). Given the fragmented nature of the European Commission, a distinction will be made between the EU Commissioner (including his/her cabinet) and the civil servants in the DGs, who represent the core of the European bureaucracy and are responsible for most of the preparatory work. Obviously, this framework provides a somewhat simplified version of the political reality. Also within these five venues, one could identify different access points. An actor could focus on the EU Commissioner or EC DG in charge of the issue (or the EP rapporteur), but it might also be an interesting option to interact with other EU Commissioners, DGs or MEPs that have been identified as having a considerable interest in the issue at hand. Likewise, it might be easier to approach a Commissioner or MEP that originates from the same member state as the regional representation. Finally, within the permanent representation, a distinction might be made between access to the working groups and the COREPER level.

To what extent do regional representations engage in contacts with all these institutions? Results from a survey of 127 regional representations, focused on their interaction with these venues over a period of 6 months, are reported in Figure 1. A large majority of the regional representations surveyed have regular contact with EU institutions and the PR of their home country, as they interact with these venues at least on a monthly basis. If we consider the relative importance of these different venues, regional representations appear to have most contact with the civil servants of the European Commission, followed by their Permanent Representations, Members of European Parliament and Members of the Committee of the Regions. The high level of interaction with EC civil servants can probably be explained by the important legislative and agenda setting role of the EC, as well as its management of EU finances (Bouwen 2009: 20). Furthermore, the high level of interaction with MEPs illustrates the growing importance of this venue as a result of its increase in legislative powers in the past two decades. The EU Commissioner clearly is a more difficult venue to reach. Nonetheless, only a few offices indicated that they had had no contact with the Commissioner or his cabinet.

[Fig 1 here] 
Notwithstanding these general trends, we also observe differences regarding the intensity of the interaction with these different venues. In terms of access and possible influence, it probably makes a significant difference whether one enjoys daily or monthly contacts. While the permanent representation is an important contact point for all regional representations, the intensity of the contacts differs considerably. Whereas some 20 percent of the regional offices have daily interactions with its PR, 50 percent meets them on a weekly basis, while 27 percent only engages in monthly interactions. Furthermore, whilst we provide a general picture here, the 'venue shopping behavior' of regional representation is also shaped by the nature of particular issues (such as its regulatory or redistributive nature), as well as the extent to which regional preferences are aligned with the policy views of specific institutions (for a more elaborate discussion and analysis of how these factors come into play, see Beyers et al. 2015).

\section{Discussion}

Although several regional representations have a high profile in Brussels and engage with various institutional venues, a considerable number of SNAs does not actively mobilize at the EU level. Furthermore, the representation of various regions is highly unsure and volatile. Several of them refrain from lobbying and solely focus on monitoring policy developments. These findings are in line with a conclusion repeatedly noted in the interest group literature, namely that interest representation tends to be biased towards a select group of interests, or skewed towards well-endowed actors (Baumgartner and Leech 1998; Schlozman et al. 2012). This tendency might have been strengthened by the recent financial crisis, and its repercussions on the available budget to open and maintain a permanent presence in Brussels. Several regions from member states where the crisis had resulted in reductions of regional budgets (such as Greece, Spain, Italy and the UK) substantially decreased or even ceased their activities in Brussels. Also, representations from some less prosperous, mostly Eastern European member states, seem to have scaled down their presence.

We would like to end this chapter with a reflection on what the mobilization of regions in Brussels implies for intergovernmental relations at the national level. Higher amounts of competence transfers, from the national to the regional level, clearly increase the likelihood that regions will open a liaison office in Brussels and establish more contacts with other European regions and EU institutions. This is a dynamic that 
could possibly stimulate bypassing behavior, implying that regions reduce the exchange of information with other regions from their member state, or seek to circumvent the national government. So far, this expectation does not appear to have materialized, as more regional autonomy does not automatically imply a higher intensity of transregional networking, or a fragmentation of member state representation. Although regional offices from more autonomous regions display a higher level of activity in Brussels, interaction with their national counterparts has remained crucial. For instance, regional offices predominantly exchange information with other regions that are geographically proximate, in particular those from their own member state (Beyers and Donas 2014). As importantly, regional representations with a higher level of selfautonomy are actually more likely to cooperate intensively with their national Permanent Representation in Brussels. Consequently, it seems that regional mobilization can also, at the same time, be highly complementary to member state representation. 
Table 1. Representation of SNAs ( $\mathrm{n}=297)$ in Brussels

\begin{tabular}{|l|l|}
\hline Representation type & N \\
\hline Liasion/Brussels office & 175 \\
\hline Transregional associations & 68 \\
\hline Complete national associations & 7 \\
\hline Partial national associations & 25 \\
\hline
\end{tabular}

Figure 1: Intensity of contact with the EU institutions ( $n=127)$
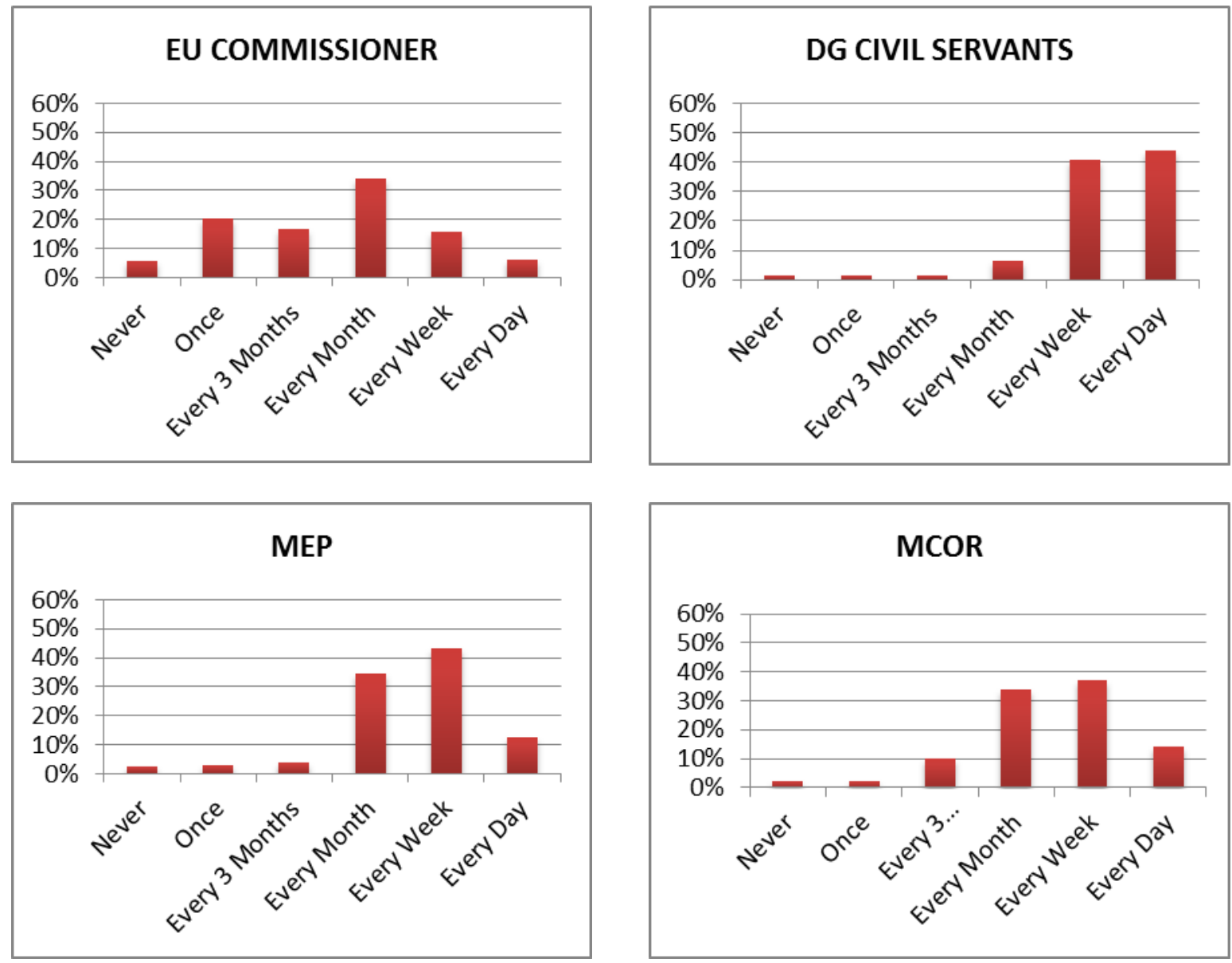


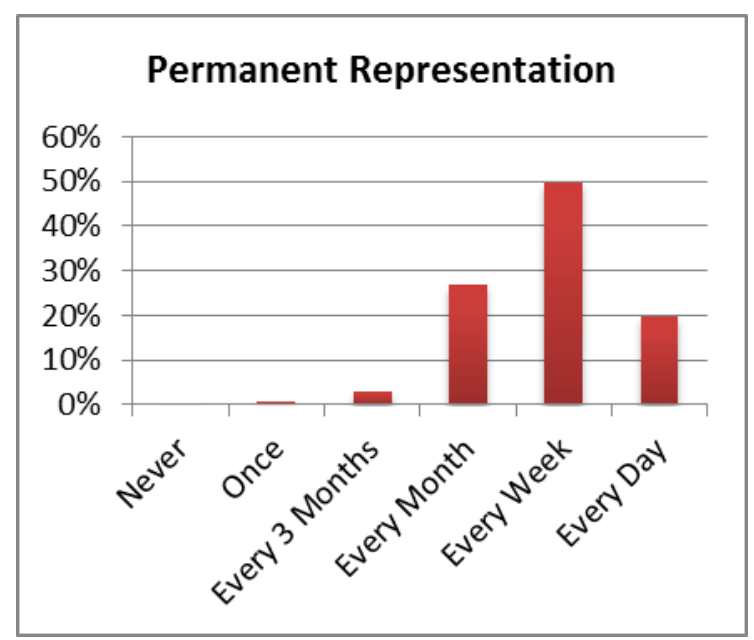




\section{References}

Bache, I. and R. Jones (2000). 'Has EU regional policy empowered the regions? A study of Spain and the United Kingdom.’ Regional \& Federal Studies, 10(3): 1-20.

Baumgartner, F. R., \& Leech, B. L. (1998) Basic Interests: the Importance of Groups in Politics and Political Science. Princeton: Princeton University Press.

Beyers , J. and P. Bursens (2013). 'How Europe shapes the nature of the Belgian Federation: differentiated EU impact triggers both co-operation and decentralization.' Regional and Federal Studies_23 (3): 271-291.

Beyers, J. and T. Donas (2014). 'Inter-regional networks in Brussels: Analyzing the information exchanges among regional offices.' European Union Politics 15(4):547-71.

Beyers , J., Donas, T. and Fraussen, B. (2015). 'No Place Like Home? Explaining Venue Selection of Regional Offices in Brussels.' Journal of European Public Policy (forthcoming).

Bouwen, P. (2009). The European Commission. In D. Coen \& J. Richardson (Eds.), Lobbying the European Union: Institutions, Actors and Issues (pp. 19-38). Oxford: Oxford University Press.

Coen, D. and J. Richardson (2009). Lobbying the European Union. Oxford, Oxford University Press.

Donas, T. and Beyers, J. (2013) 'How Regions Assemble in Brussels: The Organizational Form of Territorial Representation in the European Union.' Publius, 43(4): 527-50.

Donas, T., Fraussen, B. and Beyers, J. (2014) 'It's Not All About The Money. Explaining Varying Policy Portfolios of Regional Representations in Brussels.' Interest Groups \& Advocacy 3(1): 79-98.

Greenwood, J. (2003). Interest representation in the European Union. New York, Palgrave Macmillan.

Hooghe, L. (1995). 'Subnational Mobilization in the European Union.' West European Politics 18(3): 175-198.

Hooghe, L. (1996). Cohesion Policy and European Integration: Building Multi-Level Governance. Oxford, Oxford University Press.

Hooghe, L. and G. Marks (1996). 'Europe with the Regions: Channels of regional Representation in the European Union.' Publius - The Journal of Federalism 26(1): 73-91. 
Hooghe, L., G. Marks and A. H. Schakel (2010). The Rise of Regional Authority: a comparative study of 42 democracies (1950-2006). London, Routledge.

Hooghe, L. and G. Marks (2001). Multi-Level Governance and European Integration. Oxford, Rowman \& Littlefield Publishers, Inc.

Marks, G. (1992). 'Structural Policy in the European Community'. In A. Sbragia_EuropPolitics Institutions and Policymaking in the "New" European Community. (pp 191-206) Washington D.C., The Brookings Institution: 191-225.

Marks, G. (1993). 'Structural Policy and Multilevel Governance in the EU'. In A. Cafruny and G. Rosenthal. The State of the European Community. (pp391-410) New York, Lynne Rienner: 391-410.

Marks, G., L. Hooghe and K. Blank. (1996). 'European Integration from the 1980's : StateCentric v. Multilevel Governance.' Journal of Common Market Studies 34(3): 341-378.

Moore, C. (2008). 'A Europe of the Regions vs. the Regions in Europe: Reflections on Regional Engagement in Brussels.' Regional and Federal Studies_18(5): 517-535.

Moravcsik, A. (1998). The Choice for Europe: Social Purpose and State Power from Messina to Maastricht. Ithaca, NY, Cornell University Press.

Scharpf, F.W., 1999. Governing in Europe: effective and democratic? Oxford University Press, Oxford; New York.

Schlozman, K. L., Verba, S. and Brady, H.E. (2012) The Unheavenly Chorus. Unequal Political Voice and the Broken Promise of American Democracy. Princeton: Princeton University Press.

Tatham, M. (2008). 'Going Solo: Direct Regional Representation in the European Union.' Regional and Federal Studies 18(5): 493-515.

Tatham, M. (2010). 'With or without you'? Revisiting territorial state-bypassing in EU interest representation.' Journal of European Public Policy 17(1): 76-99.

Tatham, M. (2012). 'You do what you have to do? Salience and territorial interest representation in EU environmental affairs.' European Union Politics, 13(3): 434-450. 